\title{
Seven-year experience with chordal replacement with expanded polytetrafluoroethylene in floppy mitral valve
}

\begin{abstract}
Among 106 patients operated on for implantation of artificial mitral chordae (expanded polytetrafluoroethylene), usually associated with other traditional procedures, 82 had degenerative valve disease. Two of them had the valve replaced during the same operation because of residual regurgitation, and one patient died $(1.3 \%)$ of respiratory insufficiency. Seventy-nine patients left the hospital and were followed up to 84 months. No late deaths and only one valve-related complication were reported. This occurred in a patient who required reoperation after 18 months for sudden recurrence of mitral regurgitation caused by the rupture of natural chordae, which had been shortened during the first procedure, whereas the artificial chordae had retained their function. The clinical experience confirms positive experimental data, because this technique was reliable with lasting results. Application of artificial chordae, associated with other traditional techniques, is useful to improve the results and to extend the indications for mitral valve repair. (J THORaC Cardiovasc Surg 1994;108:37-41)
\end{abstract}

Claudio Zussa, $\mathrm{MD}^{\mathrm{a}}$ (by invitation), Elvio Polesel, $\mathrm{MD}^{\mathrm{a}}$ (by invitation), Uberto $\mathrm{Da}$ Col, $\mathrm{MD}^{\mathrm{a}}$ (by invitation), Marco Galloni, $\mathrm{BD}^{\mathrm{b}}$ (by invitation), and Carlo Valfré, $\mathrm{MD}^{\mathrm{a}}$ (by invitation), Treviso and Turin, Italy

Sponsored by Robert W. M. Frater, MD, Bronx, N.Y.

$\mathrm{C}$ hordal disease of the mitral valve has been a field for surgical research since cardiac surgery made it apparent that valve dysfunction may be produced by primitive alterations of this component of the valve apparatus. ${ }^{1-7}$ Carpentier and coworkers ${ }^{8-11}$ identified many "conservative" techniques to restore acceptable chordal function in cases of restricted or increased leaflet motion. Nevertheless, it is common to face difficulties in correcting particular abnormalities with these maneuvers alone. ${ }^{12-14}$ For

From the Cardiac Surgery Department, Treviso Regional Hospital,a Treviso, Italy, and the Veterinary Medical School, University of Turin, ${ }^{\mathbf{b}}$ Turin, Italy.

Read at the Seventy-third Annual Meeting of The American Association for Thoracic Surgery, Chicago, Ill., April 25-28, 1993.

Address for reprints: Claudio Zussa, MD, Cardiac Surgery Department, Treviso Regional Hospital, Treviso, Italy.

Copyright $\odot 1994$ by Mosby-Year Book, Inc.

$0022-5223 / 94 \$ 3.00+0 \quad 12 / 6 / 54613$ instance, in case of myxomatous degeneration of both the leaflets and related chordae, traditional procedures are sometimes inadequate. Moreover, when a diffuse fibroelastic deficiency ${ }^{8}$ is present, shortening procedures may be extremely troublesome. In these situations the more obvious solution to avoid valve replacement would be chordal replacement. ${ }^{15}$

Because of favorable experimental results obtained at the Albert Einstein College of Medicine, Bronx, New York, ${ }^{16,17}$ we started using expanded polytetrafluoroethylene sutures (e-PTFE)* at the Cardiac Surgery Department of Treviso Regional Hospital, Italy, in November 1986. After 7 years of clinical experience, we have analyzed the medium-term follow-up of the patients treated with e-PTFE chordal insertion for degenerative mitral valve disease.

*Gore-Tex sutures, W. L. Gore \& Associates, Inc., Elkton, Md. 
Table I. Demographic and clinical data

\begin{tabular}{|c|c|c|c|c|}
\hline & \multicolumn{4}{|c|}{ Cause } \\
\hline & Degenerative & Rheumatic & Infective & Ischemic \\
\hline No. of patients & 82 & 19 & 3 & 2 \\
\hline $\operatorname{Sex}(M / F)$ & $55 / 27$ & $1 / 18$ & $2 / 1$ & $1 / 1$ \\
\hline \multicolumn{5}{|l|}{ Age (yr) } \\
\hline Mean & 55.8 & 49.8 & 48.3 & 66.0 \\
\hline Range & $15-75$ & $38-61$ & $40-53$ & $64-68$ \\
\hline \multicolumn{5}{|l|}{ ECG } \\
\hline Sinus rhythm & 60 & 13 & 2 & 1 \\
\hline Atrial fibrillation & 22 & 6 & 1 & 1 \\
\hline \multicolumn{5}{|l|}{ NYHA } \\
\hline Class II & 30 & 8 & 0 & 0 \\
\hline Class III & 41 & 10 & 2 & 1 \\
\hline Class IV & 11 & 1 & 1 & 1 \\
\hline \multicolumn{5}{|l|}{ Mitral lesion } \\
\hline Stenosis & 0 & 4 & 0 & 0 \\
\hline Insufficiency & 82 & 5 & 3 & 2 \\
\hline Mixed & 0 & 10 & 0 & 0 \\
\hline \multicolumn{5}{|l|}{ Associated disease } \\
\hline Aortic valve & 0 & 3 & 0 & 0 \\
\hline Aortic + tricuspid & 0 & 5 & 0 & 0 \\
\hline $\mathrm{CAD}$ & 5 & 0 & 0 & 2 \\
\hline Atrial septal defect & 1 & 0 & 0 & 0 \\
\hline
\end{tabular}

$E C G$, Electrocardiogram; $N Y H A$, New York Heart Association; $C A D$, coronary artery disease.

Table II. Surgical procedures in degenerative disease (80 patients)

\begin{tabular}{|c|c|c|c|}
\hline & \multicolumn{2}{|c|}{$\begin{array}{c}\text { No. of } \\
\text { artificial chordae* }\end{array}$} & \multirow{2}{*}{$\begin{array}{l}\text { No. of } \\
\text { patients }\end{array}$} \\
\hline & Mean & Range & \\
\hline Site & 6.7 & $2-24$ & \\
\hline Anterior leaflet & 4.0 & $0-12$ & 54 \\
\hline Posterior leaflet & 2.9 & $0-10$ & 66 \\
\hline Commissural tissue & 0.3 & $0-4$ & 10 \\
\hline Chordal shortening & & & 1 \\
\hline Posterior quadrantectomy & & & 60 \\
\hline \multicolumn{4}{|l|}{ Annuloplasty } \\
\hline PRSA & & & 71 \\
\hline Suture annuloplasty & & & 3 \\
\hline Carpentier ring & & & 3 \\
\hline CABG & & & 5 \\
\hline Aortic crossclamp time (min) & 91.8 & $46-182$ & \\
\hline
\end{tabular}

$P R S A$, Pericardium-reinforced suture annuloplasty; $C A B G$, coronary artery bypass'grafting.

*Each e-PTFE suture generates two artificial chordae.

\section{Patients and methods}

From November 1986 to May 1993, chordal insertion with e-PTFE was used in 106 patients. The follow-up ended in November 1993. Demographic and clinical data are summarized in Table $\mathrm{I}$.

Among these patients, 82 had degenerative valve disease (myxomatous degeneration or severe fibroelastic deficiency). A rheumatic cause ( 19 cases) was present only at the beginning of our experience because rheumatic disease has been rare so far.
Since 1989 our indications in patients with rheumatic disease have changed because of evidence that long-term results of valve repair are suboptimal, with recurrent insufficiency and progression of leaflet retraction.

In the early period of our experience, two patients with degenerative disease underwent valve replacement during the same operation in which repair was attempted because of unacceptable residual regurgitation.

This report, therefore, is based on the 80 patients with degenerative disease who left the operating room after a successful mitral valve repair with e-PTFE artificial chordae.

The surgical technique has been described previously in detail $^{18}$ and may be summarized as follows. Each e-PTFE suture is anchored to the papillary muscle with a mattress technique and is reinforced with autologous pericardial pledgets on both sides of the muscle. The two strands of the suture are then fixed to the free margin of the leaflets to correspond to the unsupported areas and are reinforced with a small autologous pericardial pledget.

The length of the artificial chordae is grossly set to maintain the corresponding points of the leaflets at the same level in the ventricular cavity. After all associated procedures are completed (i.e., posterior leaflet quadrangular resection, suture annuloplasty reinforced with a strip of autologous pericardium), the ventricular cavity is filled with saline solution to close the valve and final adjustments in the length of the artificial chordae are made before the sutures are tied, to obtain a symmetric closure line and an adequate area of apposition.

The number of artificial chordae used in each patient is based on the extension of the unsupported areas. For instance, if most of the anterior leaflet requires chordal support, five or six sutures (ten or twelve chordae) should be used. Chordal and associated procedures are summarized in Table II. 


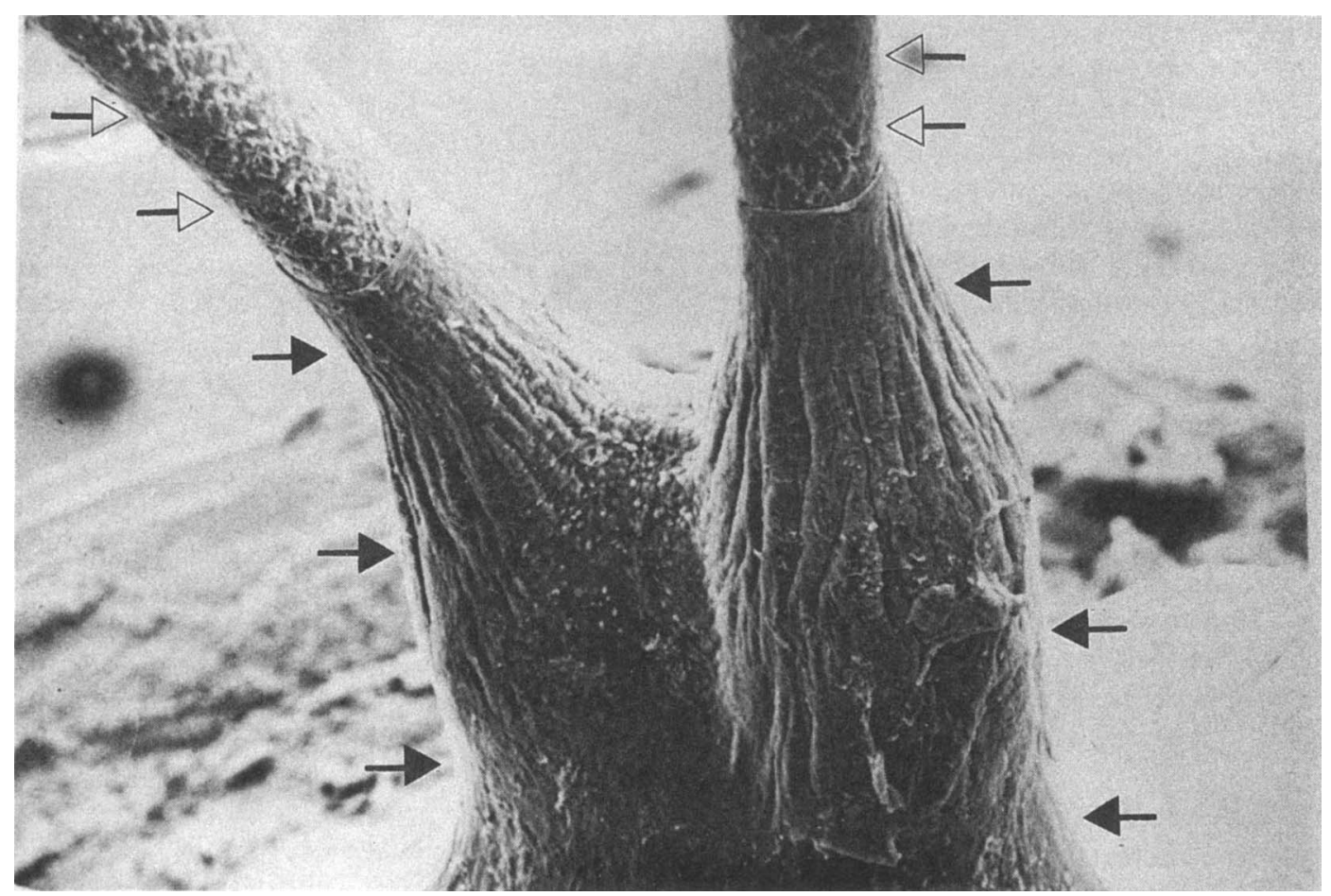

Fig. 1. Artificial chordae partially covered by a fibrous sheath and surrounded by an endothelial layer (black arrows). The segments of the suture still uncovered (open arrows) demonstrate no thrombotic depositions.

Seventy-four patients were discharged from the hospital with short-term oral anticoagulant (warfarin) therapy and five with an antiaggregant regimen. All patients were followed up every 6 to 12 months with transesophageal echocardiography (TEE).

\section{Results}

Intraoperative TEE showed no residual regurgitation in 59 patients, trivial in 19, and mild in 2 ( 2 patients with the valve replaced during the same operation are excluded). The only operative mortality $(1.2 \%)$ was related to respiratory insufficiency. No early valve-related complications were noted.

At discharge from the hospital, TEE showed disappearance of the previously reported regurgitation (4 trivial and 1 mild) in 5 cases.

Sixty patients were followed up for more than 1 year, 30 for more than 2 years, and 15 for more than 3 years. At a $100 \%$ complete mean follow-up of 30.2 months (range 6 to 84 months), no deaths or valve-related complications were reported, excluding one case of sudden recurrence of mitral regurgitation necessitating reoperation 18 months after the first procedure.

Artificial chordae were unremarkable in length and flexibility, partially covered by a fibrous sheath surrounded by an endothelial layer (Fig. 1). No thrombi or calcifications were detected. Two primary natural chordae, shortened at the first operation by traditional techniques, had ruptured a few millimeters from the emergence from the papillary muscle. Additionally, dehiscence of a suture annuloplasty was found.

At the last follow-up, 71 patients were in class I and 7 in class II of the New York Heart Association functional classification.

TEE showed a mean mitral valve gradient of $2.8 \mathrm{~mm}$ $\mathrm{Hg}$ (range 2 to $4 \mathrm{~mm} \mathrm{Hg}$ ) and a mean valve area of 2.8 $\mathrm{cm}^{2}\left(2.3\right.$ to $3.6 \mathrm{~cm}^{2}$ ). Mitral regurgitation was absent in 60 patients, trivial in 14 and mild in 4 (the patient who was reoperated on is excluded).

\section{Discussion}

The experimental evidence that e-PTFE is a reliable material to replace mitral valve chordae ${ }^{16,19,20}$ has recently been confirmed by Cochran and Kunzelman, ${ }^{21}$ who compared the viscoelastic properties of natural mitral chordae with those of different sutures. The authors found that PTFE appears to be the best substitute for mitral chordae.

The inherent characteristics of this suture (e-PTFE is one of the most inert biocompatible materials with a microporous structure that contains about $50 \%$ air by volume) allow host tissue overgrowth and infiltration in 
the internodal spaces with a secure anchoring of the fibrous sheath to the underlying artificial chorda. ${ }^{17,19,20}$

Our clinical experience and follow-up, up to 84 months, excluded thromboembolic events as well as degeneration of the new structures, with stable and satisfactory valve function after successful repair. In fact, the only reoperation was related to the failure of traditional maneuvers with late rupture of previously shortened chordae and dehiscence of an unreinforced suture annuloplasty. Since that episode we prefer to replace weakened and elongated chordae of the anterior leaflet instead of shortening them. Additionally, we now use a suture annuloplasty reinforced with a glutaraldehyde-tanned strip of autologous pericardium. ${ }^{18}$

Our increasing confidence in this technique, related to the positive follow-up and the encouraging experience reported by other authors, ${ }^{22,}{ }^{23}$ prompted us to insert more artificial chordae in each case, to obtain a more accurate correction and to prevent further progression of the disease.

In case of diffuse chordal degeneration we do not transpose posterior chordae ${ }^{10}$ but rather we insert artificial chordae in areas supported by diseased structures.

Two patients with massive mitral regurgitation caused by rupture of more than two thirds of the anterior leaflet chordae had successful valve repair with the application of six pairs of e-PTFE chordae.

Our explanted specimen confirmed experimental and clinical experiences from our group and from other authors ${ }^{17,20,22,24}$ showing that e-PTFE provides the skeleton for chordal "regeneration," although the process of fibrous overgrowth appears to be slower in human beings than in animals, as expected. So far, our indications for e-PTFE chordal implantation are as follows:

1. Anterior ruptured chordae (18 cases)

2. Elongated chordae ( 38 cases)

a. Excessively thin and numerous, as in the case of diffuse fibroelastic deficiency

b. Emerging from thin papillary muscles

3. Supportive in case of diffuse anterior and posterior myxomatous chordal degeneration (18 cases)

4. Extensive posterior leaflet flail or prolapse necessitating too large quadrangular resection ( 9 cases)

5. Association of flail anterior and prolapsed posterior cusps ( 12 cases)

A few patients had more than one indication.

The medium-term follow-up indicates that this technique is reproducible, safe, reliable, stable in results, and free of complications so far. This technique is not intended to replace other traditional successful procedures, but rather to support them by better restoring valve func- tion and increasing the number of candidates for valve repair.

\section{R E F ER E N C ES}

1. Frater RWM, Ellis FH Jr. The anatomy of the canine mitral valve: with notes on function and comparisons with other mammalian mitral valves. J Surg Res 1961;1:171-8.

2. Frater RWM. Mitral valve anatomy and prosthetic valve design. Proc Staff Meet Mayo Clin 1961;36:582-92.

3. January LE, Fisher JM, Ehrenhaft J. Mitral insufficiency resulting from rupture of normal chordae tendineae. Circulation 1962;26:1329-33.

4. Frater RWM, Berghuis J, Brown AL, Ellis FH. The experimental and clinical use of autogenous pericardium for the replacement and extension of mitral and tricuspid valve cusps and chordae. J Cardiovasc Surg 1965;6:214-28.

5. Morris JD, Penner DA, Brandt RL. Surgical correction of ruptured chordae tendineae. J THORAC CARDIOVASC SURG 1964;48:772-80.

6. Kay JH, Egerton WS. The repair of mitral insufficiency associated with torn chordae tendineae. Ann Thorac Surg 1965;1:269-76.

7. Sanders CA, Scannell JG, Harthorne JW, Austen WG. Severe mitral regurgitation secondary to ruptured chordae tendineae. Circulation 1965;31:506-16.

8. Carpentier A, Chauvaud S, Fabiani JN, et al. Reconstructive surgery of mitral incompetence: ten-year appraisal. J THORAC CARDIOVASC SURG 1980;79:338-48.

9. Carpentier A. Cardiac valve surgery-the "French correction." J ThORAC CARDIOVASC SURG 1983;86:323-37.

10. Lessana A, Romano M, Lutfalla G, et al. Treatment of ruptured or elongated anterior mitral valve chordae by partial transposition of the posterior leaflet: experience with 29 patients. Ann Thorac Surg 1988;45:404-8.

11. Deloche A, Jebara VA, Relland JYM, et al. Valve repair with Carpentier techniques: the second decade. J THORAC Cardiovasc SuRg 1990;99:990-1002.

12. Frater RWM, Gabbay S, Shore D, Factor S, Strom J. Reproducible replacement of elongated or ruptured mitral valve chordae. Ann Thorac Surg 1983;35:14-28.

13. David TE. Discussion of Lessana et al. ${ }^{10}$

14. Duran CG. Discussion of Frater et al. ${ }^{12}$

15. Frater RWM, Vetter HO, Zussa C, Dahm M. Chordal replacement in mitral valve repair. Circulation 1990; 82(Suppl):IV125-30.

16. Zussa C, Frater RWM, Galloni M, Factor SM, Valfré C. Expanded polytetrafluoroethylene as mitral valve chordae substitute. In: Proceedings of the Third World Biomaterials Congress, Kyoto, Japan, April 21-25, 1988:128.

17. Zussa C, Frater RWM, Polesel E, Galloni M, Valfré C. Artificial mitral valve chordae: experimental and clinical experience. Ann Thorac Surg 1990;50:367-73.

18. Zussa C, Polesel E, Rocco F, Galloni M, Frater RWM, Valfré C. Surgical technique for artificial mitral chordae implantation. J Card Surg 1991;6:432-8.

19. Vetter HO, Burack JH, Factor SM, Macaluso F, Frater 
RWM. Replacement of chordae tendineae of the mitral valve using the new expanded PTFE suture in sheep. In: Bodnar E, Yacoub M, eds. Biological and bioprosthetic valves. New York: Yorke Medical Books, 1986:772-85.

20. Revuelta JM, Garcia-Rinaldi R, Gaite L, Val F, Garijo F. Generation of chordae tendineae with polytetrafluoroethylene stents: results of mitral valve chordal replacement in sheep. J ThoraC CARdIOvasC SuRg 1989;97:98103.

21. Cochran RP, Kunzelman KS. Comparison of viscoelastic properties of suture versus porcine mitral valve chordae tendineae. J Card Surg 1991;6:508-13.

22. David TE, Bos J, Rakowski $H$. Mitral valve repair by replacement of chordae tendineae with polytetrafluoroethylene sutures. J THORAC Cardiovasc Surg 1991;101: 495-501.

23. Kawazoe K, Eishi K, Sasako Y, et al. Clinical experience of mitral valve reconstruction with artificial chordae implantation. Eur J Cardiothorac Surg 1992;6:297-301.

24. Maurer I, Bernhard A. PTFE sutures for mitral reconstruction: histological findings in man. Thorac Cardiovasc Surg 1991;39:73-5.

\section{Discussion}

Dr. Robert W. M. Frater (Bronx, N.Y.). I must congratulate Dr. Zussa and his colleagues for developing this technique to a mature stage. I want to make two points. First, some have wondered why we use such a narrow gauge of PTFE, fearing that it might not be strong enough, given the fact that while in the animal the goal of growing a new chorda is rapidly achieved, in the human being the timetable is clearly very different. Salisbury, some 30 years ago, demonstrated stresses in the main chordae of 60 to $200 \mathrm{mg}$, whereas the breaking strength of a 5-0 PTFE suture is over $1 \mathrm{~kg}$. Thus we do not have to fear that the narrow-gauge PTFE is not strong enough. Second, Dr. Zussa states that he uses anticoagulants in these patients. I wonder if that is really necessary, even for 3 months, in a patient in sinus rhythm with a pericardial annuloplasty and PTFE chordae that are going to be covered by the host?

Dr. Alain F. Carpentier (Paris, France). For years I have followed the efforts of Dr. Frater and his colleagues to replace the chordae tendineae of the mitral valve. Dr. Zussa has shown that these techniques have stood the test of time.

I have three questions for Dr. Zussa. Since there are alternatives to chordal replacement, is it your tendency to use PTFE chordal replacement increasingly instead of those alternative techniques, or do you use a combination of the two? Second, in the patients you have reoperated on, were you able to see some shortening of the native elongated chordae? This is theoretically possible, because when those native chordae are no longer submitted to a physiologic load, they may spontaneously shorten. Finally, have you seen any calcifications of the PTFE chordae over the long term?
Dr. Roland Hetzer (Berlin, Germany). We have not used chordal replacement but rather have tried to treat floppy valves with suture annuloplasty or plication annuloplasty. I find it interesting that you reinforce the anulus with a strip of autologous pericardium. We have done this in about our last 40 cases, and $I$ thought it was an original technique.

How do you set the dimension, the length, of this autologous pericardial strip? Since you have long-term results, have you seen any shrinkage, any calcification of this autologous pericardium in this position?

Dr. Tirone E. David (Toronto, Ontario, Canada). I have also used e-PTFE sutures to replace chordae tendineae during mitral valve repair in the past 7 or 8 years. We seldom perform chordal shortening anymore; most elongated chordae tendineae are diseased and probably should be replaced.

We presented our initial experience at a previous meeting of this Association a few years ago, and we mentioned that the synthetic chorda may not become covered with a fibrous sheath as readily as it had been shown in experimental animals based in one patient on whom we had to reoperate 9 months later. We have now reoperated on another patient 2 years after the initial valve repair and found the e-PTFE chordae totally covered with fibrous tissue; it was difficult to distinguish the artificial chordae from the native ones.

Dr. Zussa. I would like to thank all the discussants. Dr. Frater, a randomized study is needed to answer your question about anticoagulation. In our procedures, with chordae or without chordae, we prescribe anticoagulants for 3 months just to allow the endothelium to cover all sutures and other artificial materials. It is not just for the procedure by itself. But as I said, a randomized study would be needed to answer the question.

Dr. Carpentier, this is just one small tool, an additional tool that we have to repair valves. It is not intended to replace all the other confirmed, available techniques. We always use our chordae together with a quadrangular resection, annuloplasty, sliding resection, and all other kinds of procedures. We try now to use chordal replacement more than shortening, because we do not have enough experience or enough ability to use this technique of shortening. We reoperated on only one patient and we could not detect any shortening of the native elongated chordae. At reoperation and with TEE performed routinely in all patients we could not demonstrate any thickening or calcification of artificial chordae.

Dr. Hetzer, we use a Carpentier ring sizer to tailor the pericardial strip according to the body surface area (BSA) of the patient. In case of a BSA below $1.5 \mathrm{~m}^{2}$ we use a 32 sizer; when BSA is between 1.5 and $1.8 \mathrm{~m}^{2}$ a 34 sizer; and in case of a BSA above $1.8 \mathrm{~m}^{2}$ a 36 sizer. We reoperated on two patients who had a pericardial reinforced annuloplasty performed 8 and 24 months earlier for rheumatic disease. In both cases, we could not retrieve the strip at reoperation because it was completely covered by endocardium, without any sign of thickening or shrinkage. The mitral anulus was normally pliable.

Dr. David, we enjoyed your new report very much, because it confirms our experimental results. 